\title{
Experiences of in-patient mental health services: systematic review
}

Sophie Staniszewska, Carole Mockford, Greg Chadburn, Sarah-Jane Fenton, Kamaldeep Bhui, Michael Larkin, Elizabeth Newton, David Crepaz-Keay, Frances Griffiths and Scott Weich

\section{Background}

In-patients in crisis report poor experiences of mental healthcare not conducive to recovery. Concerns include coercion by staff, fear of assault from other patients, lack of therapeutic opportunities and limited support. There is little high-quality evidence on what is important to patients to inform recovery-focused care.

\section{Aims}

To conduct a systematic review of published literature, identifying key themes for improving experiences of in-patient mental healthcare.

\section{Method}

A systematic search of online databases (MEDLINE, PsycINFO and $\mathrm{CINAHL)}$ for primary research published between January 2000 and January 2016. All study designs from all countries were eligible. A qualitative analysis was undertaken and study quality was appraised. A patient and public reference group contributed to the review.

\section{Results}

Studies (72) from 16 countries found four dimensions were consistently related to significantly influencing in-patients' experiences of crisis and recovery-focused care: the importance of high-quality relationships; averting negative experiences of coercion; a healthy, safe and enabling physical and social environment; and authentic experiences of patient-centred care. Critical elements for patients were trust, respect, safe wards, information and explanation about clinical decisions, therapeutic activities, and family inclusion in care.

\section{Conclusions}

A number of experiences hinder recovery-focused care and must be addressed with the involvement of staff to provide highquality in-patient services. Future evaluations of service quality and development of practice guidance should embed these four dimensions.

\section{Declaration of interest}

K.B. is editor of British Journal of Psychiatry and leads a national programme (Synergi Collaborative Centre) on patient experiences driving change in services and inequalities.

\section{Keywords}

In-patient; mental health services; experiences; systematic review.

\section{Copyright and usage}

(c) The Royal College of Psychiatrists 2019
Patient experience is a vital source of evidence that can drive the provision of high-quality health services. ${ }^{1,2}$ Mental health inpatients report a range of experiences including fear of assault, concerns regarding coercion, limited recovery-focused support and lack of therapeutic activities. ${ }^{3-8}$ A triennial review of mental health services in England by the Care Quality Commission $(2017)^{9}$ highlighted several serious concerns about in-patient care, including wards located in older buildings not designed to meet the needs of acute patients, unsafe staffing levels and overly restrictive care in wards far from patients' homes and families.

The National Health Service (NHS) is under pressure to deliver timely, effective and affordable care with increasingly constrained resources. The National Institute for Health and Care Excellence, the NHS National Quality Board and others have restated core principles of patient-centred care including dignity, compassion, choice and autonomy, ${ }^{3-5,5-8}$ and called for a strengthening of the patient voice. Healthcare providers are now required to collect data to assess patients' experiences of care. ${ }^{9-12}$ However, the impact of this data collection on services is unclear ${ }^{13}$ because of: the diverse and poor-quality feedback methods, ${ }^{14}$ a lack of consensus about which experiences are most salient (and hence should be asked about), and limited evidence about how patient experience data can guide service improvements. ${ }^{13,15}$ Such challenges highlight the need for robust evidence to inform best practice, with clarity about the experiences of most importance to patients. In response to this need, this systematic review aimed to identify the most salient experiences of people using in-patient mental healthcare to inform the provision of high-quality services.

\section{Method}

The review was divided into a scoping review to ascertain the nature and size of the evidence base, and the main systematic review.

\section{Protocol and registration}

The EURIPIDES (Evaluating the Use of Patient Experience Data to Improve the Quality of Inpatient Mental Health Care) systematic review was registered in 2016 on PROSPERO: CRD42016033556.

\section{Scoping review}

Before the systematic review, a scoping review was conducted to ascertain the extent, range and nature of studies to map emerging key themes without describing the findings in full or performing a quality check $^{16}$ and to inform the main review. Six key authors known to be experts in mental health patient experience were contacted for new or unpublished reports and studies.

\section{Patient and Public Involvement Reference Group}

The Patient and Public Involvement Reference Group (PPIRG) included 10 service users, recruited by the Mental Health Foundation, with experience of in-patient care or caring for someone who had been an in-patient. They were invited to two meetings: first, to obtain their views on the themes identified in the scoping review, with the potential to add further concepts they felt had not been identified; and second, to obtain their opinions on themes identified in the main systematic review and to contribute to the interpretation 
Table 1 Reporting Patient and Public Involvement in the EURIPIDES study using GRIPP2

GRIPP2 ${ }^{\text {a }}$ Short Form item

Aims:

Report the aim of Patient and Public Involvement in the study

Methods:

Provide a clear description of the methods used for Patient and Public Involvement in the study

Study result outcomes:

Report the results of Patient and Public Involvement in the study, including both positive and negative outcomes

Discussion and conclusion outcomes:

Comment on the extent to which Patient and Public Involvement influenced the study overall. Describe positive and negative effects

Reflections/critical perspective:

Comment critically on the study, reflecting on the things that went well and those that did not, so others can learn from this experience
Description

(a) Ensure there is a patient voice included at all stages of the EURIPIDES study;

(b) to discuss the scoping study themes and to identify additional ones service users feel are important;

(c) to discuss the themes and sub-themes identified in the main review to ensure face and content validity.

The Patient and Public Involvement Reference Group was established by the Mental Health Foundation. Members were varying in background and experience. The Group met regularly and at key points during the study. The group were facilitated by D.C.-K. who ensured they felt able and were supported to contribute and challenge methods.

The Patient and Public Involvement Reference Group provided a strong patient and carer perspective. They critiqued the content of the themes identified in the scoping review, identifying additional areas such as boredom. They provided content and face validity of the themes and sub-themes identified in the main review. They provided real life examples of the themes from their own experiences. The Patient and Public Involvement Reference Group also checked if the themes from international studies resonated in a UK context.

The Patient and Public Involvement Reference Group was important in confirming the systematic review had identified the themes of importance to patients and carers. This was particularly important because the strength of the patient voice was uncertain in the papers reviewed.

The Patient and Public Involvement Reference Group worked well in the study. On reflection more embedded forms of involvement, with members of the group working more closely on the analysis, may have embedded the service user voice more strongly into the study and could have created the conditions for the co-production of knowledge and possibly additional sub-themes.

a. Staniszewska S, Brett J, Simera I, Seers K, Mockford C, Goodlad S, Altman DG, Moher D, Barber R, Denegri S, Entwistle A, Littlejohns P, Morris C, Suleman R, Thomas V, Tysall C. GRIPP2 reporting checklist: tools to improve reporting of patient and public involvement in research. BMJ 2017; 358: 3453 .

of our findings. A full description of the patient involvement in the study is reported using the GRIPP2 Short Form Checklist in Table 1.

\section{Identification of studies for the systematic review}

Guided by the themes that emerged from the scoping review, search terms and a search strategy were developed and applied to the databases MEDLINE, CINAHL and PsycINFO. An example of search terms and results is reported in Fig. 1. Reference lists of included papers were scanned. The search deviated from the protocol in that only three of five databases were searched due to the large numbers of abstracts retrieved (Web of Science and Embase were not used).

\section{Inclusion and exclusion criteria}

All study designs were considered if papers included experiences of current or former in-patients of mental health institutions. No restrictions were applied based on country. Articles were included if they reported primary research, were peer reviewed and published in English between January 2000 and January 2016. Papers were excluded if they were not primary studies, based on pre- 2000 data, included children and adolescents (aged under 18 years) or were not in the English language. Where study participants included both in- and out-patients, only data regarding in-patient experiences were extracted. Reviews (Table A.1) were noted and reference lists scanned, but excluded from the review to avoid bias.

\section{Study selection}

Titles and abstracts were screened (C.M., G.C.), 20\% of which were independently cross-checked for agreement before obtaining fulltext articles (S.S. and C.M.). Full texts were obtained where the abstract was unclear. Any disagreements could be resolved by consensus (C.M., G.C. and S.S.) but no disagreements occurred.

\section{Data extraction}

The data extracted, using Microsoft Excel (version 2013), included citation details, sample recruitment and research methods, findings related to key concepts and any other emerging concepts (C.M.).

\section{Quality and risk of bias in individual studies}

The quality of the studies were evaluated by the Critical Appraisal Skills Programme (CASP) Qualitative Checklist, ${ }^{17}$ undertaken by C.M. Because of the heterogeneity of the included studies, many of which were descriptive in their approach, this checklist provided an appropriate basis for comparison between studies. The only question change in the CASP checklist was from 'Is the qualitative methodology appropriate for this study?' to 'Is the methodology appropriate for this study?'

\section{Data analysis}

The scoping review informed the development of a thematic framework, which guided but did not restrict the review. A narrative synthesis of the themes was undertaken. ${ }^{18}$ As the researcher read each study, an initial preliminary synthesis of the study was undertaken and emerging sub-themes were identified. The researcher was then able to compare themes and sub-themes within and across studies and further develop them into the main themes. Themes were summarised in a descriptive form, allowing for the findings of all review studies, regardless of study design, to be aggregated and summarised. We used the concept of data saturation to help us decide when to complete data extraction. Saturation of data is judged to have happened at a point where no new themes are being identified in the studies when compared with what has already been extracted. ${ }^{7}$ It is a useful approach for large reviews where the addition of further papers is unlikely to change key findings.

\section{Results}

\section{PPIRG}

Key themes identified in the scoping review were discussed in detail by group members who critiqued their content and identified additional areas such as boredom. The PPIRG provided content and 


\begin{tabular}{|c|c|c|}
\hline Results & Search type & Actions \\
\hline 1 & exp Inpatients/ or inpatient*.mp. & 73820 \\
\hline 2 & service user*.mp. & 2556 \\
\hline 3 & patient/ & 17869 \\
\hline 4 & exp "Commitment of Mentally III"/ & 6286 \\
\hline 5 & involuntary.mp. & 10996 \\
\hline 6 & 1 or 2 or 3 or 4 or 5 & 108766 \\
\hline 7 & exp Hospitals, Psychiatric/ or psychiatric.mp. & 218311 \\
\hline 8 & psychiatry.mp. or Psychiatry/ & 74187 \\
\hline 9 & Mental Disorders/ & 139896 \\
\hline 10 & 7 or 8 or 9 & 341433 \\
\hline 11 & exp Patient Satisfaction/ & 67505 \\
\hline 12 & $\begin{array}{l}\text { (satisf* or experience*).mp. [mp=title, abstract, original title, name of substance word, } \\
\text { subject heading word, keyword heading word, protocol supplementary concept word, } \\
\text { rare disease supplementary concept word, unique identifier] }\end{array}$ & 930899 \\
\hline 13 & 11 or 12 & 933891 \\
\hline 14 & 6 and 10 and 13 & 3204 \\
\hline 15 & limit 14 to yr="2000-Current" & 2181 \\
\hline 16 & limit 15 to english language & 1943 \\
\hline
\end{tabular}

\section{Fig. 1 Example of search strategy from MEDLINE.}

face validity for the identified themes and provided real-life examples of the themes from their own experiences. The PPIRG also provided an opportunity to check if the themes identified from international studies resonated in a UK context.

\section{The systematic review}

A total of 4979 abstracts were screened and 116 papers fulfilled the inclusion criteria (Fig. 2). Two consecutive sifts were conducted due to an error in the first search of the PsycINFO database omitting 2980 hits which was identified after the first sift was completed. The first sift of 1999 hits resulted in 72 relevant papers for the review; 11 papers were from same studies. ${ }^{19-29}$ Following this, the second sift of 2980 abstracts resulted in an additional 44 studies fitting the criteria (total $n=116$ ). Drawing on the principles of data saturation, ${ }^{30}$ additional studies that repeated themes already identified were excluded from the main review. In total, eight studies added new themes and were included at this stage. 


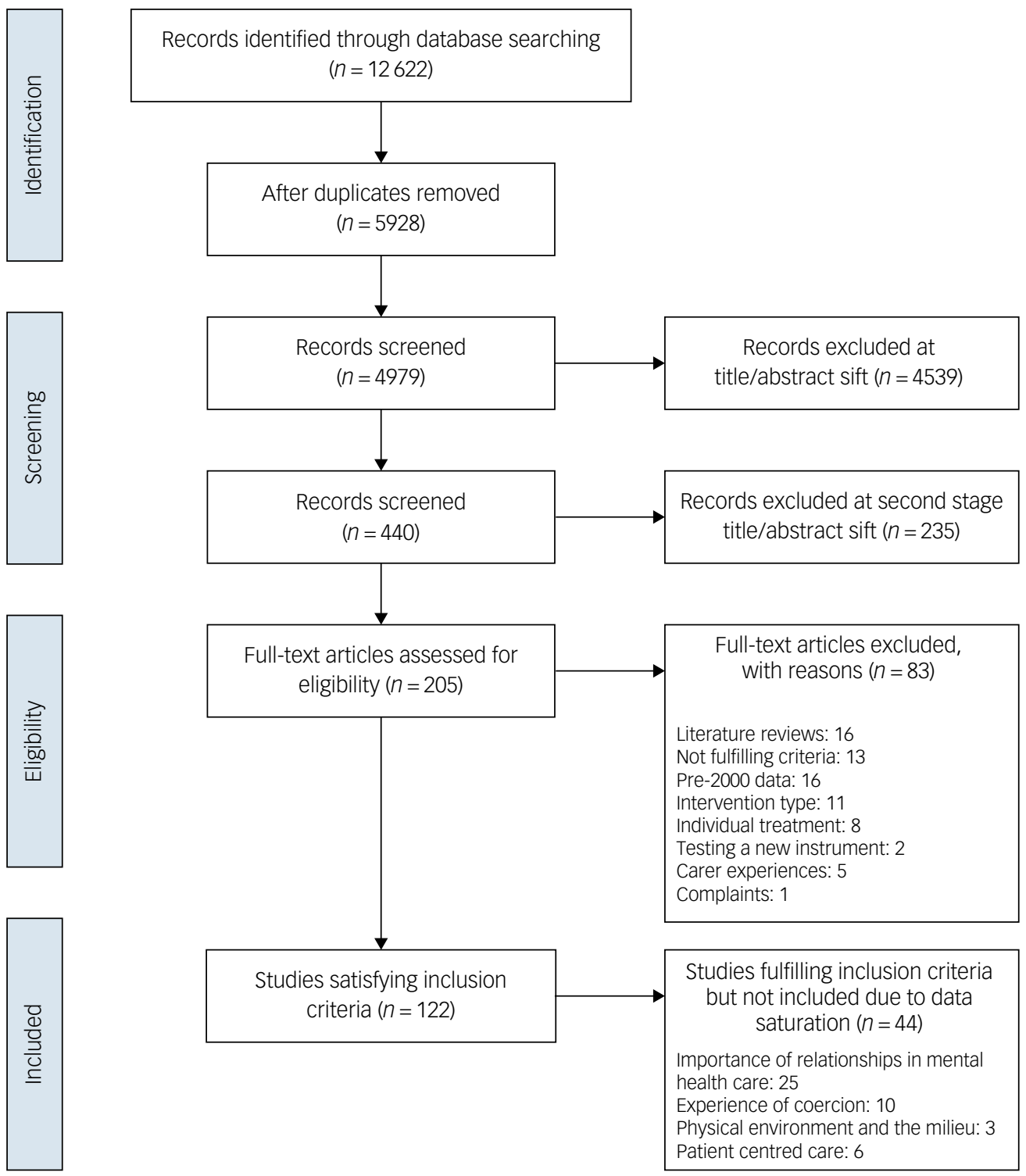

Fig. 2 PRISMA (Preferred Reporting Items for Systematic Reviews and Meta-Analyses) 2009 flow diagram.

A total of 16 systematic reviews (Table A.1) which investigated in-patient experience were identified. In total, 72 studies were included in the review, a third of which were from the $\mathrm{UK}^{24-47}(n=24)^{19-21,25,27,31-49}$ (Supplementary Table 1 available at https://doi.org/10.1192/bjp.2019.22). Although studies using qualitative methods were most common (Table A.1), studies using patient experience questionnaires and patient record data were also included. The CASP checklist identified many of the papers as being of medium to poor quality.

\section{Timing of data collection in included studies}

Little information was provided about the timing of data collection in over a third of papers (37\%), other than describing participants as inpatients at the time. ${ }^{25-27,31,32,35,36,43,44,48-63}$ Data were mostly collected just before, ${ }^{28,29,45,64-73}$ immediately after discharge $\mathrm{e}^{20,45,59,74,75}$ or from former in-patients. $22,23,34,37-39,41,42,46,47,63,76-80$ This suggests that patients were recovering when experiences were elicited. In three studies, data collection coincided with a ward event (e.g. refurbishment). ${ }^{81-83}$ A number of studies ( $n=12,17 \%$ ) collected data shortly after an event such as admission, ${ }^{19,21,84-86}$ seclusion, sedation or restraint. ${ }^{24,33,87-92}$

\section{Identification of key themes}

Patient experiences were categorised into four overarching themes or dimensions of experience: the importance of high-quality relationships; averting negative experiences of coercion; a healthy, safe and enabling physical environment and ward milieu; and authentic experiences of patient-centred care. These key themes accompanied by sub-themes are described in detail below.

\section{The importance of high-quality relationships}

The importance of high-quality relationships was the most consistently reported theme.

Important factors in developing such relationships with staff included being treated with respect, feelings of stability, recognising

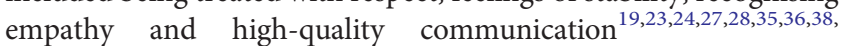
$39,51,55,60,61,63,78,87,90$ with staff who patients felt were trustworthy, reliable $^{35,63,69}$ or helpful. ${ }^{27,51,54,62}$ Good staff-patient relationships facilitated the in-patient care pathway in mental health institutions ${ }^{28,35,39,51,68}$ and reduced the use of coercive measures. ${ }^{35,45,78}$ Ward rounds were an important setting for staff-patient interaction and patients reported these as helpful and informative. ${ }^{44}$ 
Potential barriers to therapeutic relationships included: genderspecific problems - male nursing staff were not welcome if the patient had a history of abuse by male perpetrators ${ }^{36,78}$ or where gender-specific cultural barriers existed (e.g. a Muslim woman supervised by a male nurse); ${ }^{68}$ lack of meaningful communication - where communication was compromised due to differences in culture, language, religion, ${ }^{34,39,57,68}$ through use of coercive measures $^{33,60}$ or where technical language used by staff was not easily understood; ${ }^{19}$ absence of regular ward staff - patients were upset by the absence of regular ward staff due to office duties, shift working, reliance on temporary staff $^{23,24,27,28,35-37,39,45,46,51,54,55,63,69}$ and having extended waits to speak to staff ${ }^{24,36,46,54,77,80,82}$ particularly at ward rounds; ${ }^{43}$ poor staff attitude - where patients complained that staff ignored them, ${ }^{57,87,88,91}$ displayed indifference ${ }^{24}$ or insufficient understanding of patients; ${ }^{78}$ inconsistent staff behaviour reports of staff interpreting ward rules inconsistently, causing confusion; $;^{19,23,27,31,33,36,46,49,82,91}$ staff abuse - some patients reported abuse by staff, including provocation, bullying, shouting or belittling of patients. ${ }^{19,23,27,28,33,39,56,62,78,79,83,87,88}$

Relationships with other patients and with relatives: Patients relied on other patients for information about ward activities and rules, to share experiences and when debriefing after group sessions. ${ }^{22,45,77,82,83}$ However, arguments and violence between patients $^{36,39,48}$ generated fear and isolation for some, causing them to retreat to their rooms for safety or to abscond. ${ }^{23,37,39,49,65,80}$

Isolation from family caused distress. Patients reported that having a friend or family member with them would have helped with orientation ${ }^{79}$ and they could have helped staff with assessments and treatment plans. ${ }^{22,38,53}$ However, family members felt left out of decision-making about care. ${ }^{92}$

\section{Averting negative experiences of coercion}

The second main theme was concerned with experiences of coercion. All patients expected to be treated as 'normal human beings ${ }^{24,29,77}$ and addressed professionally, including during restraint. ${ }^{87}$ Patients wanted the reasons for coercive measures to be communicated so they could understand them as this helped some patients trust staff and feel safe. ${ }^{46,67,75,79,87}$ Patients valued persuasion over threats of force ${ }^{60}$ and coercion, ${ }^{78}$ which could bring back memories of past history of violence and neglect. ${ }^{33,88,89}$

Where coercive measures were discussed in the studies, these included experiences of sedation, seclusion and restraint. It has been reported that Black and minority ethnic patients are more likely to experience coercion than White patients.

Ethnicity: Two studies examined the commonly held perception that Black and minority ethnic patients experienced more coercion on admission than other patients. ${ }^{21,74}$ The findings were not conclusive: although hospitals in the UK with higher proportions of Black and minority ethnic patients employed more coercive practices, this was independent of individual patient ethnicity. ${ }^{21,74}$

Sedation: Some patients recognised that medication was important for the in-patient care pathway. ${ }^{20,39,41}$ Some trusted staff to decide on appropriate sedation, ${ }^{32,52}$ whereas others felt empowered to decide on timing and dose of medication when administered on an 'as needed' basis. ${ }^{32}$ However, patients also voiced concerns that included lack of communication about consent, information about medication and advanced wishes; ${ }^{39,52}$ lack of confidentiality regarding medication; $;^{32,42}$ perceived overmedication ${ }^{32,39,41,46,47,52,69}$ (including overlooked or ignored reports of side effects); $;^{28,41}$ and fear of harm during forced medication, ${ }^{20,32,39,54,60,78}$ for example patients in crisis reported a fear of being raped by staff or of dying. ${ }^{20,41,78,88}$

Seclusion: Some patients reported seclusion as helpful or necessary ${ }^{24,57,79,88}$ and that they felt safe as staff were nearby. ${ }^{24,57,88,90}$ Patient concerns included having insufficient information about the reasons for seclusion ${ }^{23,24,46,57,88}$ before or after the event. ${ }^{24,57}$ Seclusion was perceived as a punishment ${ }^{79}$ and associated with limited contact; ${ }^{57,88}$ lack of concern by staff; ${ }^{89}$ degradation and humiliation, e.g. lack of facilities $\mathrm{s}^{24,57,89}$ or being stripped of clothing in front of staff members; ${ }^{61,79,89,91}$ and violation of rights ${ }^{88}$ and dignity. ${ }^{61}$

Restraint: Restraint was described as forcible manual or mechanical restraint and typically involved several staff, mostly nurses ${ }^{23,60,78,88,92}$ but occasionally security staff. ${ }^{78,92}$ Restraint was described negatively ${ }^{25,33,78}$ and fear of restraint prevented patients from seeking help earlier. ${ }^{33}$ There was a risk of harm if mechanical restraints were used, ${ }^{87}$ although these were not used in all countries. Talking with staff following restraint or being allowed to examine records of the event was considered helpful. ${ }^{33}$

In addition to the use of coercive measures, patients also described perceived punishment by staff ${ }^{19,35,41,80,91}$ in the form of the removal of leave entitlements, ${ }^{35}$ removal of furniture and personal items ${ }^{41,91}$ and not being able to stay up in the evening. ${ }^{19,80}$ Patients described this as a violation of their rights. ${ }^{23,57,58,88}$

\section{A healthy, safe and enabling physical environment and ward milieu}

The third main theme focused on a healthy, safe and enabling environment. This contributed to how relatives felt when visiting, ${ }^{92}$ how patients felt about themselves ${ }^{39}$ and how they reacted to treatment. ${ }^{36,39,42}$ Johansson et al (2003) ${ }^{63}$ argued that the physical environment was as important to patients as receiving satisfactory care. A number of studies reported that patients saw hospital as a 'sanctuary ${ }^{80}$ or a 'safe space ${ }^{362}$ where they could have time to reflect away from day-to-day stressors, ${ }^{38,50}$ be kept safe ${ }^{19,39,48,54}$ and experience a caring, therapeutic environment. ${ }^{80}$

Patients felt that their in-patient care pathway was aided by connection to the 'real world' ${ }^{\text {'1 }}$ and that being made to feel 'normal' $24,28,51,77$ was important. This included being allowed to walk around hospital grounds. ${ }^{39,80}$ Older establishments often had extensive grounds and patients reported that access to these spaces resulted in less need for medication. ${ }^{32}$ Access to a place of worship was comforting, ${ }^{51,68}$ as was freedom to make small decisions ${ }^{31,41}$ such as making snacks ${ }^{62}$ or hot drinks. ${ }^{36}$ Private bedrooms were important, ${ }^{80}$ being near windows enabled ward-bound patients to enjoy the outside and fresh air, ${ }^{83}$ and appropriate use of colour was described as conducive to recovery. ${ }^{80}$ An environment where staff and patients mixed together reduced feelings of stigma $^{51}$ and encouraged favourable interactions. ${ }^{63}$

Patients reported several environmental problems that were not conducive to recovery-focused care. Some of these were associated with arguments and violence between patients. ${ }^{36,39,48}$ Other environmental problems included noise from doorbells, alarms and telephones. ${ }^{82}$ Poor positioning of the nurses' stations often created physical divisions between patients and staff, reducing interaction. ${ }^{61,80,92}$ Communal spaces sometimes lacked privacy for visiting relatives or opportunities for physical activity, ${ }^{49}$ especially for those under close observation. ${ }^{92}$

There were also contradictory reports. In several studies, some patients described hospital as a place of confinement rather than therapy. ${ }^{19,29,36,37,39,42,80}$ There were analogies with prison $^{29,36,39,42,80}$ and punishment. ${ }^{37,39}$ This was particularly so in 
secure units with a lack of outside space ${ }^{39}$ and where more patients were admitted compulsorily. ${ }^{29}$

Ward milieu: Related to environment was the experience of ward milieu, which was shaped by the conduct of staff. Staff provided structure, order and safety ${ }^{82}$ and were responsible for creating a congenial atmosphere. ${ }^{54}$ Feeling safe was a prime concern to patients $^{48,65}$ who perceived wards to be safe when they viewed staff as trustworthy, ${ }^{35}$ caring and supportive. ${ }^{35,38}$ Wards were sometimes criticised as being too busy ${ }^{36,49,54}$ and reactive to events such as restraint, ${ }^{56,79,92}$ seclusion ${ }^{91}$ or violence. ${ }^{23,58,80}$ Patients felt vulnerable to the latter, ${ }^{23,37,39}$ fearful of other patients ${ }^{49,78}$ and worried about security of belongings. ${ }^{36,65,80}$ Fear contributed to withdrawing within the ward ${ }^{49,81}$ or leaving hospital. ${ }^{37,80}$

Ward routines also shaped patients' experiences. The day ${ }^{51}$ was often structured to include individual and group therapies as well as other activities, e.g. puzzles, conversation or listening to music. ${ }^{92}$ Evenings were typically less structured. ${ }^{51}$ Some patients relished the leisure time ${ }^{24,38,50,54}$ and some took this as a time for personal reflection. ${ }^{38,51,57}$ However, others were uneasy ${ }^{38,51}$ and reported insufficient $^{36,49}$ activity. ${ }^{23,24,39,49,68}$ The location of the hospital being close to family - was important to patients ${ }^{79}$ and they appreciated the inclusion of, and support from, families. ${ }^{22,38,53}$

Boredom: 'Boredom' or having little to do was mentioned in several studies. ${ }^{23,24,27,41,51,54,59,68,80,82,83,91}$ Patients suggested that inactivity slowed the in-patient care pathway, ${ }^{59}$ reduced selfefficacy, ${ }^{41}$ exacerbated symptoms ${ }^{80}$ and was related to aggression and violence on the ward. ${ }^{23}$ Some patients reported that inactivity encouraged poor health outcomes, e.g. saying that they would eat, sleep or smoke but not exercise. ${ }^{24,59,80,83}$

\section{Authentic experiences of patient-centred care}

The final theme brought together a collection of sub-themes focused on authentic experiences of patient-centred care, which included shared decision-making, sensitivity to gender and culture and the provision of information.

Shared decision-making: Two studies reported that patients' involvement in treatment decisions was associated with positive experiences of care. ${ }^{50,65}$

Gender and cultural differences: Patients wanted to be understood and seen as individuals, and this was framed in respect of their gender, ethnicity and religion. ${ }^{33,34,68,78}$ Some patients described cultural differences in perceptions of privacy, and reported concern that staff had not recognised or responded to their discomfort in accepting care from differently gendered staff, ${ }^{68}$ for example during restraint and sedation, ${ }^{33}$ or for women with a history of sexual abuse by male perpetrators. ${ }^{78}$ More positively, female patients tended to prefer single-gender wards (where they felt $\mathrm{safer}^{36}$ ). Where this was not available, female patients were satisfied on mixed wards if they had access to a quiet room, if their privacy was respected and if they had access to personal hygiene products. ${ }^{81}$ Faith also mattered: prayer and rituals (e.g. hand washing) offered comfort to some patients ${ }^{68}$ but were not always understood or accommodated by staff. ${ }^{34}$

Provision of information: There were several reports in which patients felt they had not received sufficient information about their diagnosis, ${ }^{23,65,69,87}$ treatment, ${ }^{20}$ treatment plan, ${ }^{23,32,52,57,60,65,69,87,88,90,91}$ choices or rights. ${ }^{20,46,53,64,86}$ Timing was also important as patients found it difficult to understand or remember this information when unwell. ${ }^{45,69}$

\section{Discussion}

The aim of this review was to identify the most salient aspects of inpatient experience to support improvements in care in ways that are conducive to recovery-focused care. To the best of our knowledge this is the largest review of its type in the UK and internationally, with 72 included studies, of which a third were from the UK. A strength of the review was the involvement of the PPIRG who provided important face and content validity checks and were able to identify additional areas of experience, such as boredom, which could be built into the main review.

The review makes an important contribution to the field of mental health in-patient experiences through the identification of four key, interlinked themes: the importance of high quality relationships; averting negative experiences of coercion; a healthy, safe and enabling physical environment and ward milieu; and authentic experiences of patient-centred care. These themes and their associated sub-themes represent the active ingredients of a high-quality mental health in-patient experience (as well as the common causes of very poor experiences). The identified themes can be used to design and deliver high-quality services, provide content for the development of robust patient experience questionnaires or inform qualitative methods that aim to evaluate salient aspects of patient experience. They provide evidence for the development of practice guidance that supports the implementation of high-quality services.

A consistent thread across all four themes was the key role of staff in facilitating a high-quality patient experience. However, staff operate within the context of a wider system that needs to support the delivery of care. It was not always possible to understand this context from the studies reviewed as many did not provide such wider contextual information. This would have been useful, particularly in understanding why some studies reported very negative experiences and others reported more positive experiences. Future studies might consider reporting contextual information to aid interpretation.

It is important to note that the findings of studies relating to discharge appeared to be influenced by the research design, with questionnaires identifying high levels of satisfaction whereas experiences captured using qualitative methods were described differently. Future studies should pay careful attention to the way in which design might affect the reporting of experiences.

\section{Limitations}

A limitation of this review, common to all secondary research, is that it is reliant on the conduct and content of primary studies which may have included biases that we could not account for. Few studies mentioned the involvement of patients in data collection $^{20,39,46,79}$ and research design,,$^{20,27,39,46,79}$ and the study authors' professional perspective is often unreported. It is therefore unclear to what extent a study finding reflects the patient voice or whether it predominantly reflects the researchers' interpretation of their data. Ensuring greater clarity about whose voice is represented, as a means of minimising bias, represents an important methodological challenge for future research. In future reviews, the case could be made to focus on studies where there is evidence of a strong patient voice in the conduct and interpretation of the study.

Although we used the concept of data saturation to decide when to stop data extraction, it is always possible that other papers contained nuances in themes that were unintentionally omitted. The risk of bias in this review may have been partially mitigated by our scoping review which identified key authors and included a citation search of their papers and other literature reviews. In addition, 
the PPIRG provided important assurance of face and content validity.

Our study relies on secondary analysis of qualitative data. The findings we have presented are drawn from the reports from participants in primary studies. Many of these claims (e.g. the perceived role of good relationships in reducing a range of unwanted outcomes, the role of boredom in exacerbating those outcomes) are reported across multiple primary sources. However, an important limitation of secondary research involves the gaps that exist in studies. A key gap in this review was the lack of experiences from people of Black and minority ethnic groups, which appears to be under-researched. Future studies should ensure they build ethnicity into their design.

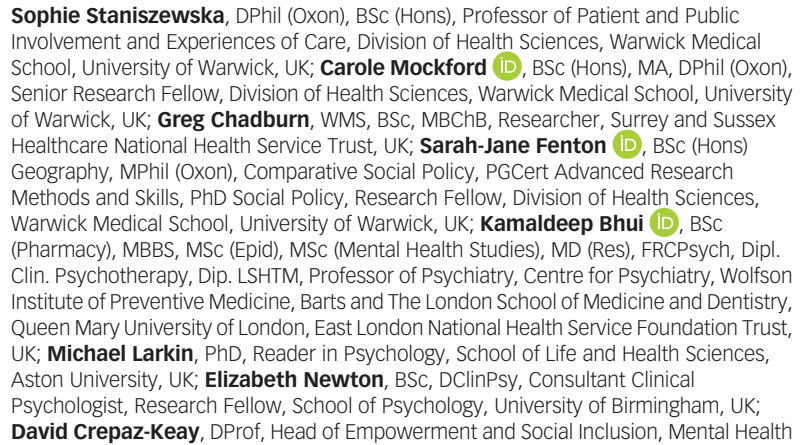

Foundation, UK; Frances Griffiths, MB, BS, PhD, Professor of Medicine in Society, Division of Health Sciences, Warwick Medical School, University of Warwick, UK; Scott Weich, MBBS, MSC, MD, FRCPsych, Professor of Mental Health, Division of Health Sciences, Warwick Medical School, University of Warwick; and School of Health and Related Research (SCHARR), University of Sheffield, UK

Correspondence: Sophie Staniszewska, Warwick Research in Nursing, Warwick Medical School, Division of Health Sciences, University of Warwick, Coventry CV4 7AL, UK. Email: sophie.staniszewska@warwick.ac.uk

First received 22 Dec 2017, final revision 19 Dec 2018, accepted 6 Jan 2019

\section{Funding}

S.S. is part-funded by NIHR CLAHRC West Midlands. K.B. was (in part) supported by the National Institute for Health Research (NIHR) Collaboration for Leadership in Applied Health Research and Care (CLAHRC) North Thames at Bart's Health NHS Trust. The views expressed are those of the author(s) and not necessarily those of the NHS, the NIHR or the Department of Health and Social Care.

\section{Supplementary material}

Supplementary material is available online at https://doi.org/10.1192/bjp.2019.22

\section{Acknowledgements}

We thank the Patient and Carer Reference Group members, who have been key to the development of this review. We thank them for all their inputs and insights. The results are stronger through their involvement.

\section{Appendix}

\begin{tabular}{|c|c|c|c|c|c|}
\hline Author & Date & Focus of review & $\begin{array}{l}\text { Number } \\
\text { studies }\end{array}$ & Years searched & Key findings: headings or themes from findings \\
\hline Binnema $^{93}$ & 2004 & Psychiatric patients and boredom & $\begin{array}{r}\text { Not stated } \\
\text { but ?18 }\end{array}$ & $\begin{array}{r}\text { Appears to be } \\
1994-2003\end{array}$ & $\begin{array}{l}\text { Boredom is a lack of experience of meaning; many } \\
\text { psychiatric patients experience boredom and lack } \\
\text { opportunities to experience meaning. This } \\
\text { indicates a lack in the therapeutic potential of the } \\
\text { hospital environment which needs to change }\end{array}$ \\
\hline Cutliffe et $a^{94}$ & 2015 & $\begin{array}{l}\text { Evaluations of in-patient mental health } \\
\text { care experiences in six countries }\end{array}$ & Not stated & Not stated & $\begin{array}{l}\text { Convergence and congruence in patient experience } \\
\text { evaluations, overall disturbing picture of in-patient } \\
\text { mental healthcare, major disconnect between } \\
\text { policy and practice, problems caused by a } \\
\text { multitude of variables, can learn from therapeutic } \\
\text { relationships }\end{array}$ \\
\hline Duncan et $a l^{95}$ & 2010 & $\begin{array}{l}\text { Cochrane review: Shared decision- } \\
\text { making interventions for people with } \\
\text { mental health conditions }\end{array}$ & 2 & All to 2008 & $\begin{array}{l}\text { Effects of interventions: clinical outcomes; health } \\
\text { service-related outcome: rate of readmission to } \\
\text { hospital; secondary outcomes: level of consumer } \\
\text { involvement in decision-making process, } \\
\text { consumer satisfaction with information provided, } \\
\text { provider satisfaction, consumer concordance with } \\
\text { treatment plan, consultation time }\end{array}$ \\
\hline Ford et $a 9^{96}$ & 2015 & $\begin{array}{l}\text { Experience of compulsory treatment } \\
\text { and implications for recovery- } \\
\text { orientated practice }\end{array}$ & 5 & 2000 onwards & $\begin{array}{l}\text { Views of the justification of compulsory detention, } \\
\text { power imbalance, lack of information or choice }\end{array}$ \\
\hline Gerolamo $^{97}$ & 2004 & $\begin{array}{l}\text { Patient outcomes after treatment in } \\
\text { acute care psychiatric hospitals and } \\
\text { wards }\end{array}$ & 47 & $1991-2004$ & $\begin{array}{l}\text { Readmission, rehospitalisation, recidivism; symptom } \\
\text { and function improvement; client satisfaction; } \\
\text { suicide and self-injury }\end{array}$ \\
\hline Hopkins et $a l^{98}$ & 2009 & $\begin{array}{l}\text { Responsiveness as context to } \\
\text { understand patient perceptions and } \\
\text { expectations to in-patient mental } \\
\text { healthcare }\end{array}$ & 10 & $1998-2008$ & $\begin{array}{l}\text { Respect for dignity, confidentiality, autonomy, prompt } \\
\text { attention, amenities, access to social networks, } \\
\text { choice of provider }\end{array}$ \\
\hline $\begin{array}{l}\text { Katsakou and } \\
\text { Priebe }^{99}\end{array}$ & 2007 & $\begin{array}{l}\text { Patient experiences of involuntary } \\
\text { hospital admission and treatment }\end{array}$ & 5 & $\begin{array}{l}\text { Selected papers } \\
\text { are from } \\
\text { 2001-2003 }\end{array}$ & $\begin{array}{l}\text { Lack of autonomy and not included in decision- } \\
\text { making, quality of care and not being cared for, } \\
\text { emotional impact of involuntary treatment and } \\
\text { feeling devalued, respect and autonomy, being } \\
\text { cared for and treatment benefits, being a human } \\
\text { being like other people }\end{array}$ \\
\hline
\end{tabular}


Table A.1 (Continued)

\begin{tabular}{|c|c|c|c|c|c|}
\hline Author & Date & Focus of review & $\begin{array}{l}\text { Number } \\
\text { studies }\end{array}$ & Years searched & Key findings: headings or themes from findings \\
\hline $\begin{array}{l}\text { McHale and } \\
\quad \text { Felton }^{100}\end{array}$ & 2010 & $\begin{array}{l}\text { Factors affecting attitudes towards self- } \\
\text { harm }\end{array}$ & 19 & $\begin{array}{l}\text { Papers from } \\
\text { 1998-2009 }\end{array}$ & $\begin{array}{l}\text { Lacking education/ training, role expectations and } \\
\text { clinical culture, perception of health needs, } \\
\text { knowledge of self-harm, education and training } \\
\text { use, dissatisfaction with care }\end{array}$ \\
\hline $\begin{array}{l}\text { Maatta }{ }^{101} \\
\text { (abstract only } \\
\text { available) }\end{array}$ & 2009 & $\begin{array}{l}\text { Exploring male and female patients' } \\
\text { experiences of psychiatric hospital } \\
\text { care: a critical analysis of the } \\
\text { literature }\end{array}$ & 5 & Not in abstract & $\begin{array}{l}\text { Treatment specifically related to women, to keep a } \\
\text { facade, and single-gender or mixed ward }\end{array}$ \\
\hline Newman et al ${ }^{102}$ & 2015 & $\begin{array}{l}\text { Mental health patients' experience of } \\
\text { mental healthcare }\end{array}$ & 34 & 2008-2012 & $\begin{array}{l}\text { Acknowledging a mental health problem and seeking } \\
\text { help, building relationships through participation in } \\
\text { care, working towards continuity of care }\end{array}$ \\
\hline Omer et al ${ }^{103}$ & 2015 & $\begin{array}{l}\text { Continuity of care versus specialist } \\
\text { systems }\end{array}$ & 21 & $1985-2013$ & $\begin{array}{l}\text { Hospitalisation, length of stay, transition of care, and } \\
\text { staff and patient views. With regard to patient } \\
\text { views, there were more positive reports for } \\
\text { continuity of care }\end{array}$ \\
\hline $\begin{array}{l}\text { Sequeira and } \\
\quad \text { Halstead }^{104}\end{array}$ & 2002 & Restraint and seclusion & 23 & $1975-2001$ & Client's experience of seclusion, restraint \\
\hline Strout ${ }^{105}$ & 2010 & $\begin{array}{l}\text { Experience of being physically } \\
\text { restrained }\end{array}$ & 12 & 1966-2009 & $\begin{array}{l}\text { Negative psychological impact, re-traumatisation, } \\
\text { perceptions of unethical practices, broken spirit }\end{array}$ \\
\hline Sturrock ${ }^{106}$ & 2010 & $\begin{array}{l}\text { Experiences of restraint in in-patient } \\
\text { areas }\end{array}$ & 5 & $\begin{array}{l}\text { 2000-March } \\
2009\end{array}$ & $\begin{array}{l}\text { Distressing; should be debriefed; can lead to } \\
\text { potentially abusive situations; engendered fear, } \\
\text { anxiety and rage; incidents could be prevented }\end{array}$ \\
\hline $\begin{array}{l}\text { Van der Merwe } \\
\text { et al }{ }^{107}\end{array}$ & 2009 & Views on locked doors & 11 & Up to 2008 & $\begin{array}{l}\text { Advantages of locked doors; disadvantages of locked } \\
\text { doors by patients, by staff; aggressive incidents } \\
\text { and the door status; patients' satisfaction with } \\
\text { treatment and the door status; patients' symptoms } \\
\text { and the door status. }\end{array}$ \\
\hline $\begin{array}{l}\text { Van Der Merwe } \\
\text { et } a l^{108}\end{array}$ & 2013 & $\begin{array}{l}\text { Improving seclusion practice - staff and } \\
\text { patient views }\end{array}$ & 39 & 1960-2006 & $\begin{array}{l}\text { Patient and staff perception of seclusion, } \\
\text { improvement suggestions }\end{array}$ \\
\hline
\end{tabular}

\section{References}

1 Rethink. Future Perfect: Mental Health Service Users Set out a Vision for the 21st Century. Rethink, 2005.

2 Royal College of Psychiatrists. Improving Inpatient Mental Health Services for Black and Minority Ethnic Patients: Recommendations to Inform Accreditation Standards. Royal College of Psychiatrists, 2010.

3 MIND. Listening to Experience: An independent Inquiry into Acute and Crisis Mental Healthcare. MIND, 2011.

4 Commission for Healthcare Audit and Inspection. The Pathway to Recovery: A Review of NHS Acute Inpatient Mental Health Services. Commission for Healthcare Audit and Inspection, 2008.

5 Care Quality Commission. Monitoring the Mental Health Act in 2012/13. Care Quality Commission, 2014

6 Commission for Healthcare Audit and Inspection. Count me in 2008: Results of the 2008 National Census of Inpatients in Mental Health and Learning Disability Services in England and Wales. Commission for Healthcare Audit and Inspection, 2008

7 Staniszewska S, Boardman F, Gunn L, Roberts J, Clay D, Seers K, Brett J, Avital L, Bullock I, O'Flynn N. The Warwick Patient Experiences Framework: patientbased evidence in clinical guidelines. Int J Qual Health Care 2014; 26: 151-7.

8 National Institute for Health and Care Excellence (NICE). Service User Experience in Adult Mental Health: Improving the Experience of Care for People Using Adult NHS Mental Health Services. NICE, 2011.

9 Care Quality Commission. The State of Care in Mental Health Services 2014 to 2017. Care Quality Commission, 2017.

10 Curtis S, Gesler W, Priebe S, Francis S. New spaces of inpatient care for people with mental illness: a complex 'rebirth' of the clinic? Health Place 2009; 15: $340-8$

11 Barbato A, Bajoni A, Rapisarda F, D'Anza V, De Luca LF, Inglese C, et al. Quality assessment of mental health care by people with severe mental disorders: participatory research project. Community Ment Health J 2014; 50: 402-8.

12 Bramesfeld A, Klippel U, Seidel G, Schwartz FW, Dierks M. How do patients expect the mental health service system to act? Testing the WHO responsiveness concept for its appropriateness in mental health care. Soc Sci Med 2007; 65: 880-9.

13 Coulter A, Locock L, Ziebland S, Calabrese J. Collecting data on patient experience is not enough: they must be used to improve care. BMJ 2014; 348: g2225.
14 National Health Service (NHS) England. NHS England Review of the Friends and Family Test. NHS England, 2014.

15 Boiko O, Campbell JL, Elmore N, Davey AF, Roland M, Burt J. The role of patient experience surveys in quality assurance and improvement: a focus group study in English general practice. Health Expect 2015; 18: 1982-94.

16 Arksey H, O'Malley R. Scoping studies: towards a methodological framework. Int J. Soc Res Methodol 2005; 8: 19-32.

17 Critical Appraisal Skills Programme (CASP). CASP Qualitative Checklist. CASP, 2007. Available at: http://www.casp-uk.net/.

18 Sandelowski $\mathrm{M}$, Voils $\mathrm{Cl}$, Barroso J. Defining and designing mixed research synthesis studies. Res Sch 2006; 13: 29

19 Katsakou C, Marougka S, Garabette J, Rost F, Yeeles K, Priebe S. Why do some voluntary patients feel coerced into hospitalisation? A mixed-methods study. Psychiatry Res 2011; 187: 275-82.

20 Katsakou C, Rose D, Amos T, Bowers L, McCabe R, Oliver D, et al. Psychiatric patients' views on why their involuntary hospitalisation was right or wrong: a qualitative study. Soc Psychiatry Psychiatr Epidemiol 2012; 47: 1169-79.

21 Bennewith O, Amos T, Lewis G, Katsakou C, Wykes T, Morriss R, et al. Ethnicity and coercion among involuntarily detained psychiatric in-patients. $\mathrm{Br} J$ Psychiatry 2010; 196: 75-6.

22 Kauppi K, Hätönen $\mathrm{H}$, Adams CE, Välimäki M. Perceptions of treatment adherence among people with mental health problems and health care professionals. J Adv Nurs 2015; 71: 777-88.

23 Kontio R, Anttila M, Lantta T, Kauppi K, Joffe G, Valimaki M. Toward a safer working environment on psychiatric wards: service users' delayed perspectives of aggression and violence-related situations and development ideas. Perspect Psychiatr Care 2014; 50: 271-9.

24 Kontio R, Joffe G, Putkonen H, Kuosmanen L, Hane K, Holi M, et al. Seclusion and restraint in psychiatry: patients' experiences and practical suggestions on how to improve practices and use alternatives. Perspect Psychiatr Care 2012; 48: 16-24.

25 Whittington R, Bowers L, Nolan P, Simpson A, Neil L. Approval ratings of inpatient coercive interventions in a national sample of mental health service users and staff in England. Psychiatr Serv 2009; 60: 792-8.

26 Bowers L, Haglund K, Muir-Cochrane E, Nijman H, Simpson A, Van Der Merwe M. Locked doors: a survey of patients, staff and visitors. J Psychiatr Ment Health Nurs 2010; 17: 873-80.

27 Stewart D, Burrow H, Duckworth A, Dhillon J, Fife S, Kelly S, et al. Thematic analysis of psychiatric patients' perceptions of nursing staff. Int J Ment Health Nurs 2015; 24: 82-90. 
28 Wyder M, Bland R, Blythe A, Matarasso B, Crompton D. Therapeutic relationships and involuntary treatment orders: service users' interactions with health-care professionals on the ward. Int J Ment Health Nurs 2015; 24: 181-9.

29 Wyder M, Bland R, Herriot A, Crompton D. The experiences of the legal processes of involuntary treatment orders: tension between the legal and medical frameworks. Int J Law Psychiatry 2015; 38: 44-50.

30 Dixon-Woods $M$, Agarwal S, Jones D, Young B, Sutton A. Synthesising qualitative and quantitative evidence: a review of possible methods. J Health Serv Res Policy 2005; 10: 45-53.

31 Alexander J. Patients' feelings about ward nursing regimes and involvement in rule construction. J Psychiatr Ment Health Nurs 2006; 13: 543-53.

32 Baker JA, Lovell K, Easton K, Harris N. Service users' experiences of 'as needed' psychotropic medications in acute mental healthcare settings. J Adv Nurs 2006; 56: 354-62

33 Bonner G, Lowe T, Rawcliffe D, Wellman N. Trauma for all: a pilot study of the subjective experience of physical restraint for mental health inpatients and staff in the UK. J Psychiatr Ment Health Nurs 2002; 9: 465-73.

34 Bowl R. The need for change in UK mental health services: South Asian service users' views. Ethnicity Health 2007; 12: 1-19.

35 Chorlton E, Smith I, Jones SA. Understanding how people who use illicit drugs and alcohol experience relationships with psychiatric inpatient staff. SoC Psychiatry Psychiatr Epidemiol 2015; 50: 51-8.

36 Cutting $P$, Henderson C. Women's experiences of hospital admission. $J$ Psychiatr Ment Health Nurs 2002; 9: 705-12.

37 Duggins R, Shaw I. Examining the concept of patient satisfaction in patients with a diagnosis of schizophrenia: a qualitative study. Psychiatric Bull 2006; 30 $142-5$.

38 Fenton K, Larkin M, Boden ZVR, Thompson J, Hickman G, Newton E. The experiential impact of hospitalisation in early psychosis: service-user accounts of inpatient environments. Health Place 2014; 30: 234-41.

39 Gilburt H, Rose D, Slade M. The importance of relationships in mental health care: a qualitative study of service users' experiences of psychiatric hospital admission in the UK. BMC Health Serv Res 2008; 8: 92.

40 Greenwood N, Hussain F, Burns T, Raphael F. Asian in-patient and carer views of mental health care. Asian views of mental health care. J Ment Health 2000; 9: 397-408.

41 Hughes R, Hayward M, Finlay WML. Patients' perceptions of the impact of involuntary inpatient care on self, relationships and recovery. J Ment Health 2009; 18: 152-60.

42 Jones A, Crossley D. In the mind of another shame and acute psychiatric inpatient care: an exploratory study. A report on phase one: service users. $J$ Psychiatr Ment Health Nurs 2008; 15: 749-57.

43 Labib PLZ, Brownell L. Factors affecting patient satisfaction with the psychiatric ward round: retrospective cross-sectional study. Psychiatr Bull 2009; 33: 295-8.

44 Milner G, Jankovic J, Hoosen I, Marrie D. Patients and staff understanding of general adult psychiatry ward rounds. J Ment Health 2008; 17: 492-7.

45 Nolan P, Bradley E, Brimblecombe N. Disengaging from acute inpatient psychiatric care: a description of service users' experiences and views. J Psychiatr Ment Health Nurs 2011; 18: 359-67.

46 Ridley J, Hunter S. Subjective experiences of compulsory treatment from a qualitative study of early implementation of the Mental Health (Care \& Treatment) (Scotland) Act 2003. Health Soc Care Community 2013; 21: 509-18.

47 Russo J, Rose D. 'But what if nobody's going to sit down and have a real conversation with you?' Service user/survivor perspectives on human rights. J Public Ment Health 2013; 12: 184-92.

48 Stenhouse RC. 'Safe enough in here?': patients' expectations and experiences of feeling safe in an acute psychiatric inpatient ward. J Clin Nurs 2013; 22 3109-19.

49 Kennedy J, Fortune T. Women's experiences of being in an acute psychiatric unit: an occupational perspective. Br J Occup Ther 2014; 77: 296-303.

50 Borge L, Hummelvoll JK. Patients' experience of learning and gaining personal knowledge during a stay at a mental hospital. J Psychiatr Ment Health Nurs 2008; 15: 365-73.

51 Borge L, Fagermoen MS. Patients' core experiences of hospital treatment: wholeness and self-worth in time and space. J Ment Health 2008; 17: 193-205.

52 Cleary M, Horsfall J, Jackson D, O'Hara-Aarons M, Hunt GE. Patients' views and experiences of pro re nata medication in acute mental health settings. Int $J$ Ment Health Nurs 2012; 21: 533-9.

53 Cleary M, Hunt GE, Escott P, Walter G. Receiving difficult news. Views of patients in an inpatient setting. J Psychosoc Nurs Ment Health Serv 2010; 48: 40-8.

54 Donald F, Duff C, Lee S, Kroschel J, Kulkarni J. Consumer perspectives on the therapeutic value of a psychiatric environment. J Ment Health 2015; 24: 63-7.
55 Gunasekara I, Pentland T, Rodgers T, Patterson S. What makes an excellent mental health nurse? A pragmatic inquiry initiated and conducted by people with lived experience of service use. Int J Ment Health Nurs 2014; 23: 101-9.

56 Lucas M, Stevenson D. Violence and abuse in psychiatric in-patient institutions: a South African perspective. Int J Law Psychiatry 2006; 29 195-203.

57 Ntsaba GM, Havenga Y. Psychiatric in-patients' experience of being secluded in a specific hospital in Lesotho. Health SA Gesondheid 2007; 12: 3-12.

58 Robins CS, Sauvageot JA, Cusack KJ, Suffoletta-Maierle S, Frueh BC. Consumers' perceptions of negative experiences and "sanctuary harm" in psychiatric settings. Psychiatr Serv 2005; 56: 1134-8.

59 Roe D, Ronen Y. Hospitalization as experienced by the psychiatric patient: a therapeutic jurisprudence perspective. Int J Law Psychiatry 2003; 26: 317-32.

60 Sibitz I, Scheutz A, Lakeman R, Schrank B, Schaffer M, Amering M. Impact of coercive measures on life stories: qualitative study. Br J Psychiatry 2011; 199: 239-44.

61 Thibeault CA, Trudeau K, d'Entremont M, Brown T. Understanding the milieu experiences of patients on an acute inpatient psychiatric unit. Arch Psychiatr Nurs 2010; 24: 216-26.

62 Thomas SP, Shattell M, Martin T. What's therapeutic about the therapeutic milieu? Arch Psychiatr Nurs 2002; 16: 99-107.

63 Johansson H, Eklund M. Patients' opinion on what constitutes good psychiatric care. Scand J Caring Sci 2003; 17: 339-46.

64 Brunero S, Lamont S, Fairbrother G. Using and understanding consumer satisfaction to effect an improvement in mental health service delivery. $J$ Psychiatr Ment Health Nurs 2009; 16: 272-8.

65 Cleary M, Horsfall J, Hunt GE. Consumer feedback on nursing care and discharge planning. J Adv Nurs 2003; 42: 269-77.

66 Eytan A, Bovet L, Gex-Fabry M, Alberque C, Ferrero F. Patients' satisfaction with hospitalization in a mixed psychiatric and somatic care unit. Eur Psychiatry 2004; 19: 499-501.

67 Georgieva I, Mulder CL, Wierdsma A. Patients' preference and experiences of forced medication and seclusion. Psychiatr Q 2012; 83: 1-13.

68 Greenwood N, Hussain F, Burns T, Raphael F. Asian in-patient and carer views of mental health care. Asian views of mental health care. J MentHealth 2000; 9: 397-408.

69 McGuinness D, Dowling M, Trimble T. Experiences of involuntary admission in an approved mental health centre. J Psychiatr Ment Health Nurs 2013; 20: 726-34.

70 Olusina AK, Ohaeri JU, Olatawura MO. Patient and staff satisfaction with the quality of in-patient psychiatric care in a Nigerian general hospital. Soc Psychiatry Psychiatr Epidemiol 2002; 37: 283-8.

71 Smith D, Roche E, O'Loughlin K, Brennan D, Madigan K, Lyne J, et al. Satisfaction with services following voluntary and involuntary admission. $J$ Ment Health 2014; 23: 38-45

72 Sorgaard KW. Satisfaction and coercion among voluntary, persuaded/pressured and committed patients in acute psychiatric treatment. Scand J Caring Sci 2007; 21: 214-9.

73 Strauss JL, Zervakis JB, Stechuchak KM, Olsen MK, Swanson J, Swartz MS, et al. Adverse impact of coercive treatments on psychiatric inpatients' satisfaction with care. Community Ment Health J 2013; 49: 457-65.

74 Anders RL, Olson T, Bader J. Assessment of acutely mentally ill patients' satisfaction of care: there is a difference among ethnic groups. Issues Ment Health Nurs 2007; 28: 297-308.

75 Steinert T, Birk M, Flammer E, Bergk J. Subjective distress after seclusion or mechanical restraint: one-year follow-up of a randomized controlled study. Psychiatr Serv 2013; 64: 1012-7.

76 Bramesfeld A, Wedegartner F, Elgeti $\mathrm{H}$, Bisson S. How does mental health care perform in respect to service users' expectations? Evaluating inpatient and outpatient care in Germany with the WHO responsiveness concept. BMC Health Serv Res 2007; 7: 99.

77 Lilja L, Hellzen O. Former patients' experience of psychiatric care: a qualitative investigation. Int J Ment Health Nurs 2008; 17: 279-86.

78 Looi G-ME, Engström Å, Sävenstedt S. A self-destructive care: self-reports of people who experienced coercive measures and their suggestions for alternatives. Issues Ment Health Nurs 2015; 36: 96-103.

79 Mayers $\mathrm{P}$, Keet N, Winkler G, Flisher AJ. Mental health service users' perceptions and experiences of sedation, seclusion and restraint. Int J SOC Psychiatry 2010; 56: 60-73.

80 Muir-Cochrane E, Oster C, Grotto J, Gerace A, Jones J. The inpatient psychiatric unit as both a safe and unsafe place: implications for absconding. Int J Ment Health Nurs 2013; 22: 304-12.

81 Kulkarni J, Gavrilidis E, Lee S, Van Rheenen TE, Grigg J, Hayes E, et al. Establishing female-only areas in psychiatry wards to improve safety and quality of care for women. Australas 2014; 22: 551-6. 
82 Lindgren B-M, Aminoff C, Graneheim UH. Features of everyday life in psychiatric inpatient care for self-harming: an observational study of six women. Issues Ment Health Nurs 2015; 36: 82-8.

83 Shattell M, Melanie Andes M, Thomas S. How patients and nurses experience the acute care psychiatric environment. Nurs Inq 2008; 15: 242-50.

84 Giacco D, Fiorillo A, Del Vecchio V, Kallert T, Onchev G, Raboch J, et al. Caregivers' appraisals of patients' involuntary hospital treatment: European multicentre study. Br J Psychiatry 2012; 201: 486-91.

85 Svindseth MF, Dahl AA, Hatling T. Patients' experience of humiliation in the admission process to acute psychiatric wards. Nord J Psychiatry 2007; 61: 47-53.

86 Thapinta D, Anders RL, Wiwatkunupakan S, Kitsumban V, Vadtanapong S. Assessment of patient satisfaction of mentally ill patients hospitalized in Thailand. Nurs Health Sci 2004; 6: 271-7.

87 Chien WT, Chan CW, Lam LW, Kam CW. Psychiatric inpatients' perceptions of positive and negative aspects of physical restraint. Patient Educ Couns 2005; 59: 80-6.

88 Ezeobele IE, Malecha AT, Mock A, Mackey-Godine A, Hughes M. Patients' lived seclusion experience in acute psychiatric hospital in the United States: a qualitative study. J Psychiatr Ment Health Nurs 2014; 21: 303-12.

89 Holmes D, Kennedy SL, Perron A. The mentally ill and social exclusion: a critica examination of the use of seclusion from the patient's perspective. Issues Ment Health Nurs 2004; 25: 559-78.

90 Iversen VC, Sallaup T, Vaaler AE, Helvik A-S, Morken G, Linaker O. Patients' perceptions of their stay in a psychiatric seclusion area. J Psychiatr Intensive Care 2011; 7: 1-10.

91 Meehan T, Vermeer C, Windsor C. Patients' perceptions of seclusion: a qualitative investigation. J Adv Nurs 2000; 31: 370-7.

92 O'Brien L, Cole R. Mental health nursing practice in acute psychiatric closeobservation areas. Int J Ment Health Nurs 2004; 13: 89-99.

93 Binnema D. Interrelations of psychiatric patient experiences of boredom and mental health. Issues Ment Health Nurs 2004; 25: 833-42.

94 Cutliffe J, Santos J, Kozel B, Taylor P, Lees D. Raiders of the Lost Art: a review of published evaluations of inpatient mental health care experiences emanating from the United Kingdom, Portugal, Canada, Switzerland, Germany and Australia. Int J Ment Health Nurs 2015; 24: 375-85.

95 Duncan E, Best C, Hagen S. Shared decision making interventions for people with mental health conditions. Cochrane Database Syst Rev 2010: N.PAG-N. PAG 1p.
96 Ford S-B, Bowyer T, Morgan P. The experience of compulsory treatment: the mplications for recovery-orientated practice? Ment Health Soc Inclusion 2015; 19: 126-32.

97 Gerolamo AM. State of the science: outcomes of acute inpatient psychiatric care. Arch Psychiatr Nurs 2004; 18: 203-14.

98 Hopkins JE, Loeb SJ, Fick DM. Beyond satisfaction, what service users expect of inpatient mental health care: a literature review. J Psychiatr Ment Health Nurs 2009: 16: 927-37.

99 Katsakou C, Priebe S. Patient's experiences of involuntary hospital admission and treatment: a review of qualitative studies. Epidemiol Psichiatr Soc 2007; 16: $172-8$.

100 McHale J, Felton A. Self-harm: what's the problem? A literature review of the factors affecting attitudes towards self-harm. J Psychiatr Ment Health Nurs 2010; 17: 732-40.

101 Maatta S. Exploring male and female patients' experiences of psychiatric hospital care: A critical analysis of the literature. Issues Ment Health Nurs 2009; 30: $174-80$

102 Newman D, O'Reilly P, Lee SH, Kennedy C. Mental health service users' experiences of mental health care: an integrative literature review. J Psychiatr Ment Health Nurs 2015; 22: 171-82.

103 Omer S, Priebe S. Continuity across inpatient and outpatient mental health care or specialisation of teams? A systematic review. Eur Psychiatry 2015; 30 258-70.

104 Sequeira $\mathrm{H}$, Halstead S. Restraint and seclusion: service user views. J Adult Protection 2002; 4: 15-24

105 Strout TD. Perspectives on the experience of being physically restrained: an integrative review of the qualitative literature. Int J Ment Health Nurs 2010; 19 : $416-27$

106 Sturrock A. Restraint in inpatient areas: the experiences of service users. Ment Health Pract 2010; 14: 22-6.

107 Van der Merwe M, Bowers L, Jones J, Simpson A, Haglund K. Locked doors in acute inpatient psychiatry: a literature review. J Psychiatr Ment Health Nurs 2009: 16: 293-9.

108 Van Der Merwe M, Muir-Cochrane E, Jones J, Tziggili M, Bowers L. Improving seclusion practice: implications of a review of staff and patient views. $J$ Psychiatr Ment Health Nurs 2013; 20: 203-15

100 words

\section{0 words...on psychobiotics}

Timothy G. Dinan

That gut microbes, collectively called the microbiota, influence brain development and functioning is viewed as a new paradigm in neuroscience with implications for psychiatry. These gut microbes communicate with the brain via a number of routes including the vagus nerve and the production of molecules such as short-chain fatty acids. In major depressive disorder the gut microbiota shows a significant decrease in microbial diversity which is associated with a peripheral inflammatory phenotype. Psychobiotics are bacteria which, when ingested in appropriate amounts, have positive mental health benefits. Preliminary studies with bacteria such as Bifidobacterium longum indicate anxiolytic activity in healthy volunteers

Copyright @ The Royal College of Psychiatrists 2019 